\title{
CARDIORESPIRATORY SYSTEM AND ANTIHYPOXIC RESISTANCE STATE IN ELDER CORONARY HEART DISEASE PATIENTS
}

\author{
Galina Voinarovska \\ State Institution "Dmitry F. Chebotarev Institute of Gerontology of the National Academy of \\ Medical Sciences of Ukraine" \\ 67 Vyshgorodska str., Kyiv, Ukraine, 04114 \\ galka.v@ukr.net
}

\begin{abstract}
The aim of the study. Evaluation of cardiorespiratory system and microcirculation state in elder CHD patients with different resistance against hypoxia.

Methods. The author has carried out a retrospective analysis of 103 CHD 60+-patients, their deaths have occurred due to cardiovascular events. Two patient groups have been formed including patients (68 persons) having kept their resistance to hypoxia (their blood $\mathrm{SO}_{2}$ level was never below $80 \%$ ) and patients ( 35 ones) with decreased resistance to hypoxia, their blood $\mathrm{SO}_{2}$ level having been dropped below $80 \%$.

Results. The life span of patients with decreased hypoxia resistance is lower comparing to ones having kept such resistance. The patients with decreased hypoxia resistance demonstrate decreased ejection fraction, increased mass of left ventricle myocardium as well as increased left ventricle volumes. Such patients show also significant increase of mean daily values of systolic, diastolic, and mean arterial pressure. Generally, the micro-circulation state in patients with decreased anti-hypoxic resistance is lower comparing to persons having kept this resistance. Simultaneously, the endothelial function of persons with decreased anti-hypoxic resistance is significantly worse. The pulmonary ventilation system patency and bronchial patency in these persons are also lowered comparing to these indices in patients with kept anti-hypoxic resistance.

Conclusions. The decrease of anti-hypoxic resistance leads to the shorter life span on elderly CHD patients. Such decreased resistance is accompanied by worsened potency of cardio-respiratory system, microcirculation, and endothelial system functioning.

Keywords: coronary heart disease (CHD), aging, cardio-respiratory system, hypoxia.
\end{abstract}

DOI: $10.21303 / 2504-5679.2020 .001418$

\section{Introduction}

The hypoxia development is a typical ageing-accompanying pathological process leading to numerous limitations concerning the course of both infection-due and non-infectious diseases including also ischemic heart damage $[1,2]$. In elderly persons, the decrease of oxygen transport function leads to the development of arterial hypoxemia and heavy tissue hypoxia causing the decrease of anti-hypoxic resistance and the development of oxygen deficiency [3, 4].

The anti-hypoxic resistance of the organism means not only the state of anti-hypoxic resistance, but also its resistance against a lot of other non-favourable factors [5, 6]. The anti-hypoxic resistance is a homeostasis supporting factor in conditions of hypoxia. Such organism's resistance may be determined as a limit oxygen concentration in inspired air, the homeostasis being damaged below this concentration [7].

The hypoxia process and hypoxia beginning could be present in the majority of pathological processes and diseases $[8,9]$. For example, the development of hypoxia is a key link of cardiovascular pathologies, in particular, of the coronary heart disease CHD. The disturbance of coronary blood stream in CHD patients leads to myocardium ischemia; later the development causes the decreased functioning efficacy of the cardiovascular system. It promotes the appearance of circulatory hypoxia and hypoxia-due changes in the organism accompanying the decrease of organism's resistance against hypoxia [10].

In cases of CHD development in elderly patients, pathology-due damages caused by hypoxia are usually put on age-due changes. In such situation the development and progress of hypoxia-due disturbances in elderly CHD patients exhaust compensatory mechanisms of the organism and may be fatal $[1,11]$. 
The development of anti-hypoxic resistance is a complex process being multi-component and of different directions. Numerous investigations demonstrate important mechanisms of anti-hypoxic resistance to include, together with respiratory system, also oxygen-transporting system of blood, cardiovascular system state as well as endothelium dysfunction and changes of micro-circulation $[12,13]$. The morpho-functional state of elderly CHD patients with different anti-hypoxic resistance have been not investigated, it was quite worth to study this problem. In particular, there were no data concerning the state of cardio-respiratory system and microcirculation in elderly CHD patients with different anti-hypoxic resistance who had died because of cardiovascular events.

The aim of the study. Evaluation of cardio-respiratory system and micro-circulation state in elder CHD patients with different resistance against hypoxia who have died because of cardiovascular events.

\section{Materials and methods}

The author carried out a retrospective analysis of $103 \mathrm{CHD} 60^{+}$-patients treated during 2005-2019 of the State Institution "Dmitry F. Chebotarev Institute of Gerontology of the National Academy of Medical Sciences of Ukraine", their deaths have occurred due to cardiovascular events.

This investigation was approved by the Ethic Commission of the State Institution "Dmitry F. Chebotarev Institute of Gerontology of the National Academy of Medical Sciences of Ukraine" No. 8 (21.12.2017). The CHD diagnoses were verified according to current international protocols and to the order of the Ministry of Health of Ukraine No. 152 (02.03.2016) [14, 15]. The work was carried out in accordance with the principles of the Declaration of Helsinki.

The evaluation of anti-hypoxic resistance of our patients was realized according to the results of a hypoxic test determined [inspiration of hypoxic gas mixture with $12 \% \mathrm{O}_{2}$ during 20 min, the blood saturation $\left(\mathrm{SO}_{2}\right)$ being monitored].

Two patient groups have been formed for patients having reached the final point: patients (68 persons) having kept their resistance to hypoxia (their blood $\mathrm{SO}_{2}$ level has been never below $80 \%$ ) and patients (35 ones) with decreased resistance to hypoxia, their blood $\mathrm{SO}_{2}$ level have been dropped below $80 \%$. The $\mathrm{SO}_{2}$ level was chosen as a criterion showing the patient's decrease of anti-hypoxic resistance taking into account the following reasoning. It is known the degrees of hypoxic damaging effect are determined as compensation, sub-compensation, and de-compensation [16]. The sub-compensation phase is usually developed following the inspiration of gas mixture containing $12-12.5 \%$ of $\mathrm{SO}_{2}$ and corresponding to the blood saturation level about $78-80 \%$. According to the data of Kolchinskaya et al., the oxygen tension in tissues reaches in this case 45-50 $\mathrm{mm} \mathrm{Hg}$ and leads to tissue structural damage [17]. Consequently, the $\mathrm{SO}_{2}$ level having reached $80 \%$ is the limit level and may be used for evaluation of anti-hypoxic resistance.

The analysis of morpho-functional state of the cardiovascular system was made using two-dimensional echocardiography and daily monitoring of arterial pressure.

Pulmonary ventilation function was evaluated according to spirometry data.

The state of microcirculation and of endothelial function was studied using the laser flowmetry and the data of voluminous speed of skin blood flow using a test with reactive hyperemia.

Statistical data evaluation was realized using variation statistics approaches and the computer program Excel 2010 (Microsoft Office 2010, Product ID: 02954-076-111196, Order ID: 6368848992). All the studied indices have distributions close to normal ones; consequently, parametric statistical approaches were used. The normality of data distribution was checked using Kolmogorov-Smirnov and Shapiro-Wilk tests. Each distribution was thought to be normal in cases of $p>0.05$. Mean values $(M)$ and their errors (m) were calculated. The t-test of Student was taken for to compare quantitative indices. The differences were thought to be statistically significant at the $\mathrm{p}$ value $<0.05$.

\section{Results}

\section{1. Status of the cardiovascular system}

The analysis of results demonstrates the life span of persons with decreased anti-hypoxic resistance to be significantly shorter comparing to patients with kept resistance $(69.32 \pm 5.21$ against 
$74.49 \pm 4.07$ years, $\mathrm{p}<0.05)$. At the same time, a significant decrease of left ventricle ejection fraction, increase of left ventricle myocardium mass and of left ventricle myocardium mass index were found as well as cavity dilatation in patients died later with decreased anti-hypoxic resistance (Table 1).

Table 1

Mean values describing structural and functional myocardium state of CHD patients of elderly age with different anti-hypoxic resistance.

\begin{tabular}{ccc}
\hline Indices & Increased anti-hypoxic resistance & Kept anti-hypoxic resistance \\
\hline RF, $\%$ & $48.1 \pm 0.1$ & $50 . \pm 0.2^{*}$ \\
LVPW, cm & $1.3 \pm 0.02$ & $1.2 \pm 0.02$ \\
IVS, cm & $1.3 \pm 0,01$ & $1.2 \pm 0.01$ \\
ESV, cm & $4.01 \pm 0.02$ & $3.9 \pm 0.02^{*}$ \\
EDV, cm & $5.8 \pm 0.02$ & $5.5 \pm 0.02^{*}$ \\
LVMM, g/m ${ }^{2}$ & $277 \pm 2.2$ & $263 \pm 2.2^{*}$ \\
LVMMI, g/m
\end{tabular}

Notes: * - differences are significant comparing to the group with decreased anti-hypoxic resistance, $p<0.05$. There are presented data as M m; LVPW - posterior wall of the left ventricle; IVS - inter-ventricle septum; EDV - end diastolic volume; ESV - end systolic volume; EF - ejection fraction; LVMM - left ventricle myocardium mass; LVMMI - left ventricle myocardium mass index

Analysis of indices of daily arterial pressure monitoring in elderly CHD patients with decreased anti-hypoxic resistance demonstrates significant increase of mean daily values for systolic blood pressure (BP), diastolic BT, and mean BT comparing to elderly CHD patients having kept their anti-hypoxic resistance (Table 2). The patients with decreased anti-hypoxic resistance are also shown to have significantly higher values of mean daily pulse BT comparing to ones with kept anti-hypoxic resistance (Table 2).

Table 2

Mean values of daily AT monitoring in elderly CHD patients with different anti-hypoxic resistance

\begin{tabular}{ccc}
\hline Indices & Increased anti-hypoxic resistance & Kept anti-hypoxic resistance \\
\hline Mean daily SBP, $\mathrm{mm} \mathrm{Hg}$ & $159.0 \pm 12.7$ & $120.2 \pm 12.5^{*}$ \\
Mean daily DBP, $\mathrm{mm} \mathrm{Hg}$ & $89.2 \pm 3.75$ & $72.8 \pm 3.75^{*}$ \\
Mean daily BT $_{\text {mean }}, \mathrm{mm} \mathrm{Hg}$ & $126.33 \pm 2.7$ & $115.03 \pm 2.6^{*}$ \\
Mean daily PBP, $\mathrm{mm} \mathrm{Hg}$ & $58.76 \pm 2.2$ & $52.56 \pm 1.02^{*}$ \\
Area index & $28.7 \pm 4.7$ & $15.2 \pm 4.7^{*}$
\end{tabular}

Note: * - differences are significant comparing to the group with decreased anti-hypoxic resistance, $p<0.05$; $S B P-s y s t$ tic BP; $D B P$ - diastolic BP; $P B P$ - pulse BP. The data are presented as $M \pm m$

\section{2. State of microcirculation and endothelial function}

The analysis of conducted studies demonstrates the state of tissue perfusion on the micro-vessel level to be on the whole significantly lower in CHD patients with decreased anti-hypoxic resistance comparing to ones with kept resistance. It is proved by slight, but significant decrease of voluminous speed of skin blood flow (VSSBF) in such patients (Table 3). The VSSBF increase on the peak of reactive hyperemia in patients with decreased anti-hypoxic resistance is also less manifested comparing to ones having kept such resistance (Table 3). Simultaneously, following reactive hyperemia the recovery period in patients with decreased anti-hypoxic resistance is significantly inhibited (Table 3). 
Table 3

The state of blood flow in micro-vessels during test with reactive hyperemia in elderly CHD patients with different anti-hypoxic resistance

\begin{tabular}{ccc}
\hline Indices & Increased anti-hypoxic resistance & Kept anti-hypoxic resistance \\
\hline Background VSSBF value, $\mathrm{mL} / \mathrm{min} \times 100 \mathrm{~g}$ & $1.37 \pm 0.05$ & $1.53 \pm 0.04^{*}$ \\
VSSBF value on the peak of reaction, $\mathrm{mL} / \mathrm{min} \times 100 \mathrm{~g}$ & $3.77 \pm 0.25$ & $5.28 \pm 0.28^{*}$ \\
VSSBF, $\mathrm{mL} / \mathrm{min} \times 100 \mathrm{~g}$ & $2.42 \pm 0.13$ & $3.75 \pm 0.14^{*}$ \\
Duration of peak reaction development, $\mathrm{s}$ & $23.5 \pm 2.5$ & $14.4 \pm 21^{*}$ \\
Duration of recovery, s & $94.2 \pm 5.5$ & $117.47 \pm 6.1^{*}$
\end{tabular}

Note: * - differences are significant comparing to the group with decreased anti-hypoxic resistance, $p<0.05$; VSSBF - voluminous speed of skin blood flow. The data are presented as $M \pm m$

\section{3. Pulmonary ventilation function and bronchial patency}

The conducted studies permit to declare the pulmonary ventilation function and bronchial patency to be significantly lower in patients with decreased anti-hypoxic resistance comparing to ones having kept such resistance (Table 4).

\section{Table 4}

Mean values of indices describing pulmonary ventilation function and bronchial patency in elderly CHD patients with decreased anti-hypoxic resistance comparing to ones having kept such resistance

\begin{tabular}{ccc}
\hline Indices & Increased anti-hypoxic resistance & Kept anti-hypoxic resistance \\
\hline $\mathrm{VE}, \mathrm{L} / \mathrm{min}$ & $8.26 \pm 0.23$ & $8.47 \pm 0.34$ \\
$\mathrm{MVV}, \mathrm{L} / \mathrm{min}$ & $63.77 \pm 2.44$ & $77.82 \pm 2.29^{*}$ \\
$\mathrm{FVC}, \mathrm{L}$ & $2.62 \pm 0.28$ & $3.08 \pm 0.22^{*}$ \\
$\mathrm{FEV}, \mathrm{L} / \mathrm{s}$ & $1.62 \pm 0.21$ & $2.13 \pm 0.18^{*}$ \\
$\mathrm{FEV}_{\mathrm{l}} / \mathrm{FVC}, \%$ & $61.83 \pm 1.48$ & $69.16 \pm 2.11^{*}$
\end{tabular}

Note: * - differences are significant comparing to the group with decreased anti-hypoxic resistance, $p<0.05$. The data are presented as $M \pm m$. VE-lung ventilation during a minute; $M V V$ - maximal lung ventilation; FVC-vital lung capacity; FEV ${ }_{1}$-volume of forced respiration during the first second

\section{Discussion}

The life span decrease in elderly CHD patients with lowered anti-hypoxic resistance proves such resistance lowering to be an unfavourable risk factor. At the same time, some current investigations show the anti-hypoxic resistance of elderly CHD patients to be dependent on the state of cardiovascular system.

Hypoxia and related disturbances are a key mechanism of the CHD. The local myocardium hypoxia developed as a result of coronary arteries atherosclerosis in CHD patients leads to the lowering of myocardium function possibilities. On the other hand, it may promote the decrease of oxygen transport, development of circulatory hypoxia, and decrease of anti-hypoxic resistance. The analysis of obtained data demonstrates the anti-hypoxic resistance in elderly CHD patients to be also a result of worsened structural and functional state of myocardium.

The level of blood pressure is dependent on the state of cardiovascular system. Simultaneously, the level of blood pressure influences on oxygen transport, oxygen providing to tissues, and anti-hypoxic resistance. On the other hand, the blood pressure level is an important index for evaluation of cardiovascular risk and prediction of cardiovascular events. The BP level describes (reflects) a dynamic component of the pressure on target organs as well as an rigidity indicator of large arterial vessels. The BP increase in elderly CHD patients with decreased anti-hypoxic resis- 
tance may lead to the development of peripheral vasospasm. It is just an event being able to cause the blood flow disturbance, decrease of oxygen providing for tissues, appearance of tissue hypoxia, and decrease of anti-hypoxic resistance.

The possible causes of disturbances concerning microcirculation and endothelial function in elderly CHD patients with decreased anti-hypoxic resistance are decreased micro-vessel diameters and lowered quantity of capillary vessels as well as worsening of rheological blood properties. On the other hand, the worsening of microcirculation in patients with decreased anti-hypoxic resistance comparing to ones having kept this resistance is a result of inhibited synthesis of endothelial vasodilators and of endothelial dysfunction development. Less expressive VSSBF increase on the peak of reactive hyperemia in patients with decreased anti-hypoxic resistance as well as significantly lowered recovery potential post hyperemia are proves of worsened endothelium function due to decreased nitrogen oxide synthesis.

The obtained data testify the microcirculation disturbance and endothelium dysfunction develop a danger for oxygen providing to the organism promoting the decrease of anti-hypoxic resistance in elderly CHD patients.

Pulmonary ventilation function and bronchial patency are a key link in adaptive mechanism to hypoxic conditions in elderly CHD patients [18-20]. The reaction of lung ventilation mechanism on hypoxia is realized through chemo-receptors of the aorta arc and respiratory center responding on the decreased blood oxygen tension during the development of arterial hypoxia. The anti-hypoxic resistance is mostly due to adequacy of ventilation response on hypoxia.

The investigations showed the decreased anti-hypoxic resistance of elderly CHD patients to be a consequence of changes in pulmonary ventilation function and bronchial patency. It is confirmed by the FVC decrease in patients with decreased anti-hypoxic resistance. Reserve ventilation possibilities proved by the MVV decrease are also lower in such patients (Table 4). It is also important the bronchial patency to be significantly lower in patients with decreased anti-hypoxic resistance comparing to ones having kept it (Table 4). Consequently, it is possible the decreased pulmonary function of ventilation as well as lowered bronchial patency to be among mechanisms causing the decrease of anti-hypoxic resistance in elderly CHD patients.

The studies were limited to elucidating the features of the functioning of the cardiorespiratory system in elderly patients with coronary artery disease with reduced and preserved resistance to hypoxia.

Prospects for further research are to develop a model for predicting life expectancy in elderly patients with coronary artery disease, depending on resistance to hypoxia.

\section{Conclusions}

1. The decreased anti-hypoxic resistance leads to shortened life span in elderly CHD patients, such a fact being a risk factor of unfavourable cardiovascular events in these patients.

2. The decreased anti-hypoxic resistance in elderly CHD patients is especially due to structural and functional changes of cardio-respiratory system, microcirculation, and endothelium function. In such patients the functioning efficacy of cardio-respiratory system, microcirculation, and endothelium function are decreased.

\section{Conflict of interests}

The authors declare that they have no conflicts of interest.

\section{References}

[1] Lukyanova, L. D. (2019). Signaling mechanisms of hypoxia. Moscow: RAN, 214.

[2] Fajemiroye, J. O., Cunha, L. C. da, Saavedra-Rodríguez, R., Rodrigues, K. L., Naves, L. M., Mourão, A. A. et. al. (2018). Aging-Induced Biological Changes and Cardiovascular Diseases. BioMed Research International, 2018, 1-14. doi: http:// doi.org/10.1155/2018/7156435

[3] Korkushko, O. V., Ivanov, L. A. (1980). Gipoksiia i starenie. Kyiv: Naukova dumka, 276.

[4] Zhavoronkov, A., Li, R., Ma, C., Mamoshina, P. (2019). Deep biomarkers of aging and longevity: from research to applications. Aging, 11 (22), 10771-10780. doi: http://doi.org/10.18632/aging.102475 
[5] Meerson, F. Z. (1994). Adaptatsiia k stressu i gipoksiia. Biulleten eksperimentalnoi biologii i meditsiny, 1, 574-575.

[6] Koehler, U., Hildebrandt, O., Krönig, J., Grimm, W., Otto, J., Hildebrandt, W. et. al. (2018). Chronic hypoxia and cardiovascular risk: Clinical significance of different forms of hypoxia. Herz, 43 (4), 291-227. doi: http://doi.org/10.1007/s00059-017-4570-5

[7] Asanov, E. O. (2008). Vikovi osoblyvosti reaktsii orhanizmu na hipoksychnyi stres: mekhanizmy ta shliakhy pidvyshchennia stiikosti do hipoksii. Kyiv: In-t herontolohii AMN Ukrainy, 42.

[8] Zarubina, I. V. (2011). Modern view on pathogenesis of hypoxia and its pharmacological corection. Reviews on clinical pharmacology and drug therapy, 9 (3), 31-48.

[9] Ilyukhin, S. A., Novikov, V. E. (2012). Influence of antihypoxants on acetylsalicylic acid efficiency in acute inflammation. Vestnik Smolenskoj gosudarstvennoj medicinskoj akademii, 11 (4), 46-51.

[10] Akat, F., Fiçıcılar, H., Durak, A., Tuncay, E., Dursun, A. D. (2018). Topal Çelikkan F, et al. Intermittent hypoxia induces beneficial cardiovascular remodeling in left ventricular function of type 1 diabetic rat. The Anatolian Journal of Cardiology, 19 (4), 259-266. doi: http://doi.org/10.14744/anatoljcardiol.2018.00236

[11] Navarrete-Opazo, A., Mitchell, G. S. (2014). Therapeutic potential of intermittent hypoxia: a matter of dose. American Journal of Physiology-Regulatory, Integrative and Comparative Physiology, 307 (10), R1181-R1197. doi: http://doi.org/10.1152/ ajpregu.00208.2014

[12] Cobbs, G. A., Alexander, J. E. (2018). Assessment of oxygen consumption in response to progressive hypoxia. PLOS ONE, 13 (12), e0208836. doi: http://doi.org/10.1371/journal.pone.0208836

[13] Nikolaeva, A. A., Nikolaev, K. Iu., Popova, L. V. (2006). Sosudistaia reaktivnost i endotelialnye disfunktsii pri arterialnoi gipertenzii i ishemicheskoi bolezni serdtsa (diagnostika, lechenie i profilaktika). Novosibirsk: In-t terapii SO RAMN, 191.

[14] Pro zatverdzhennia ta vprovadzhennia medyko-tekhnolohichnykh dokumentiv zi standartyzatsii medychnoi dopomohy pry stabilnii ishemichnii khvorobi sertsia (2016). Nakaz MOZ Ukrainy No. 152. 02.03.2016. Available at: https://ips.ligazakon.net/ document/MOZ25649

[15] Montalescot, G., Sechtem, U., Achenbach, S. et. al. (2013). 2013 ESC guidelines on the management of stable coronary artery disease. European Heart Journal, 34, 2949-3003. doi: http://doi.org/10.1093/eurheartj/eht296

[16] Hrachev, V. Y., Sevriukov, Y. T. (2018). Hypoxia and hypoxemia, their causes and consequences for humans. Norwegian Journal of development of the International Science. 17, 12-30.

[17] Kolchinskaia, A. Z., Tsyganova, T. N., Ostapenko, L. A. (2003). Normobaricheskaia intervalnaia gipoksicheskaia trenirovka v meditsine i sporte. Moscow: Meditsina, 412.

[18] Lhuissier, F. J., Canoui-Poitrine, F., Richalet, J.-P. (2012). Ageing and cardiorespiratory response to hypoxia. The Journal of Physiology, 590 (21), 5461-5474. doi: http://doi.org/10.1113/jphysiol.2012.238527

[19] Prabhakar, N. R. (2013). Sensing hypoxia: physiology, genetics and epigenetics. The Journal of Physiology, 591 (9), $2245-2257$. doi: http://doi.org/10.1113/jphysiol.2012.247759

[20] Kovalevska, L. A., Horbenko, T. M. (2013). Features of hypoxic disorders in patients with chronic obstructive pulmonary disease due to concomitant diseases. Actual problems of transport medicine, 1, 107-112. Available at: http://nbuv.gov.ua/UJRN/ aptm_2013_1_15

Received date 03.08.2020

Accepted date 02.09.2020

Published date 30.09.2020
(C) The Author(s) 2020

This is an open access article under the CC BY license (http://creativecommons.org/licenses/by/4.0). 